\title{
Article
}

\section{Validation of an Arabic Version of the Self-Efficacy for Appropriate Medication Use Scale}

\author{
Hawazin Alhazzani ${ }^{1,+}{ }^{\text {, Ghaida AlAmmari }}{ }^{1}$, Nouf AlRajhi ${ }^{1}$, Ibrahim Sales ${ }^{1}{ }^{\circledR}$, Amr Jamal $^{2}{ }^{\circledR}$, \\ Turky H. Almigbal ${ }^{2}$, Mohammed A. Batais ${ }^{2}$, Yousif A. Asiri ${ }^{1}$ and Yazed AlRuthia ${ }^{1,3, *,+}$ (D) \\ 1 Department of Clinical Pharmacy, College of Pharmacy, King Saud University, P.O. Box 2454, \\ Riyadh 11451, Saudi Arabia; Hawazin.sah@gmail.com (H.A.); ghaida.alammari@outlook.com (G.A.); \\ 436204108@student.ksu.edu.sa (N.A.); isales@ksu.edu.sa (I.S.); yasiri@KSU.EDU.SA (Y.A.A.) \\ 2 Family and Community Medicine Department, College of Medicine, King Saud University, P.O. Box 3145, \\ Riyadh 12372, Saudi Arabia; amrjamal@KSU.EDU.SA (A.J.); almogbal@yahoo.com (T.H.A.); \\ drmohammed34@gmail.com (M.A.B.) \\ 3 Pharmacoeconomics Research Unit, Department of Clinical Pharmacy, College of Pharmacy, \\ King Saud University, P.O. Box 2454, Riyadh 11451, Saudi Arabia \\ * Correspondence: yazeed@ksu.edu.sa; Tel.: +966-114-677-483; Fax: +966-114-677-480 \\ $\dagger$ The first and last authors contributed equally to this work.
}

check for updates

Citation: Alhazzani, H.; AlAmmari, G.; AlRajhi, N.; Sales, I.; Jamal, A.; Almigbal, T.H.; Batais, M.A.; Asiri, Y.A.; AlRuthia, Y. Validation of an Arabic Version of the Self-Efficacy for Appropriate Medication Use Scale. Int. J. Environ. Res. Public Health 2021, 18, 11983. https://doi.org/10.3390/ ijerph182211983

Academic Editors:

Alireza Daneshkhah

Amin Hosseinian-Far, Vasile Palade and Samer A. Kharroubi

Received: 28 September 2021

Accepted: 12 November 2021

Published: 15 November 2021

Publisher's Note: MDPI stays neutral with regard to jurisdictional claims in published maps and institutional affiliations.

Copyright: (c) 2021 by the authors Licensee MDPI, Basel, Switzerland. This article is an open access article distributed under the terms and conditions of the Creative Commons Attribution (CC BY) license (https:/ / creativecommons.org/licenses/by/ $4.0 /$ )

\begin{abstract}
Background: Medication adherence is essential for optimal treatment outcomes in patients with chronic diseases. Medication nonadherence compromises patient clinical outcomes and patient safety as well as leading to an increase in unnecessary direct and indirect medical costs. Therefore, early identification of non-adherence by healthcare professionals using medication adherence scales should help in preventing poor clinical outcomes among patients with chronic health conditions, such as diabetes and hypertension. Unfortunately, there are very few validated medication adherence assessment scales in Arabic. Thus, the aim of this study was to validate a newly translated Arabic version of the Self-Efficacy for Appropriate Medication Use Scale (SEAMS) among patients with chronic diseases. Methods: In this single-center cross-sectional study that was conducted between March 2019 and March 2021 at the primary care clinics of King Saud University Medical City (KSUMC) in Riyadh, Saudi Arabia, the English version of SEAMS was translated to Arabic using the forwardbackward method and piloted among 22 adults ( $\geq 18$ yrs.) with chronic diseases. The reliability of the newly translated scale was examined using the test-retest and Cronbach's alpha methods. Exploratory and confirmatory factor analyses were conducted to examine the construct validity of the Arabic version of SEAMS. Results: The number of patients who consented to participate and filled out the questionnaire was 202. Most of the participants were males $(69.9 \%)$, aged $\geq 50$ years $(65.2 \%)$, and had diabetes (96.53\%). The 13-item Arabic-translated SEAMS mean score was $32.37 \pm 5.31$, and the scale showed acceptable internal consistency (Cronbach's alpha $=0.886$ ) and reliability (Intraclass correlation coefficient $=0.98$ ). Total variance of the 13-item Arabic-SEAMS could be explained by two factors as confirmed by the factor analysis. Conclusion: The Arabic version of SEAMS should help in detecting poor self-efficacy for medication adherence among Arabic-speaking patient populations with chronic diseases, such as diabetes and hypertension. Future studies should examine its validity among more diverse patient populations in different Arabic-speaking countries.
\end{abstract}

Keywords: medication adherence; self-efficacy; health literacy; validation studies; surveys and questionnaires; 13-item SEAMS

\section{Introduction}

Shared-decision making (SDM) has become an essential component of the patientcentered care which plays a significant role in the patient receptiveness to medical information provided by healthcare providers [1]. Therefore, it influences patient adherence to prescribed treatment regimens [2]. Medication adherence has been defined by Chakrabarti 
et al. as "the extent to which a person's behavior, taking medication, following a diet, and/or executing lifestyle changes, corresponds with agreed recommendations from a health care provider" [3]. Patient nonadherence to prescription medications has always been a persistent major issue affecting as many as $50 \%$ of patients with chronic health conditions and negatively influencing the outcomes of any treatment plan [4]. It can result in a significant burden to the healthcare system in terms of direct and indirect costs by increasing recurrent admissions and hospital visits due to lack of proper management and control of chronic illnesses [5]. There are numerous factors that lead to nonadherence, such as the inability to pay for medications, poor understanding of medication instructions, the complexity of the medication regimen, poor patient-provider relationship, and drug adverse effects [6].

Generally, patients suffering from chronic diseases tend to have higher rates of nonadherence to their prescribed medicines [7]. Low levels of education, illiteracy, and cultural and social beliefs about the illness and treatment have a significant effect upon medication adherence [7]. With an increasing prevalence of chronic diseases worldwide, the increasing burden of nonadherence to medication has become even more challenging [8]. In a systematic review and meta-analysis conducted by Abegaz et al. reported that $45.2 \%$ of patients with hypertension and $31.2 \%$ of hypertensive patients with comorbidities were nonadherent to their anti-hypertensive medications [9]. In another study that explored the prevalence of nonadherence among type 2 diabetes patients in Southwest Germany using a prospective cohort study data, around $23 \%$ of the surveyed patients were found to be nonadherent to their prescribed medicines [10].

Measuring medication adherence directly using biologic samples, such as blood or urine, is impractical and costly [11]. Therefore, the use of self-report scales to assess nonadherence among patients in general, and those with chronic diseases in particular, is crucial [12]. Since numerous self-reported factors have been reported by patients with chronic health conditions, such as hypertension and diabetes, to impede adherence to prescribed treatment regimens, it is important to include these factors in any self-report medication adherence assessment scales [13]. Commonly used self-report medication adherence assessment scales include the 4-item and 8-item Morisky Medication Adherence Scales (MMAS-8) [14], Medication Adherence Report Scale (MARS) [15], and the 13-item Self-Efficacy for Appropriate Medication Use Scale (SEAMS) [16]. The SEAMS is an English 13-question self-efficacy for medication adherence questionnaire that focuses on the patient's confidence in taking their prescribed medicines as instructed by their healthcare providers. It is a three-point scale, where 3 indicates "very confident", 2 indicates "somewhat confident", and 1 indicates "not confident". Scores range between 13 to 39 , and the higher scores indicate higher self-efficacy for medication adherence [16]. It has been validated in other languages, such as the Portuguese; however, it has not been translated and validated into Arabic [17]. Thus, the primary objective of this study was to test the validity and reliability of a newly Arabic translated version of the 13-item SEAMS among patients with chronic diseases, such as diabetes and hypertension. Additionally, the relationship between health literacy and the 13-item Arabic SEAMS score was examined.

\section{Methods}

\subsection{Study Design}

In this cross-sectional study, the visitors of the primary care clinics at King Saud University Medical City (KSUMC) - which is a large university-affiliated tertiary care institution that mainly provides free healthcare to King Saud University employees and their relatives in Riyadh, Saudi Arabia-were approached during their regular check-up visits and invited to participate in the study. Adult patients (e.g., $\geq 18$ years) with chronic diseases, such as diabetes, hypertension, dyslipidemia, asthma, chronic obstructive pulmonary disease, and cardiovascular disease, were included in the study. The patients' chronic health conditions, age, and prescription medications were checked in their electronic health records. Non-Arabic speaking patients, healthy individuals without chronic health condi- 
tions, and those who reported not taking any prescription medications were excluded from the study. In order to improve the study sample representativeness, a systematic selection of the 10th patient record from the scheduled appointments for the year of 2019 until March 2020 was conducted. Then, 319 selected files were reviewed for eligibility, resulting in a final list of 264 patients who met the inclusion criteria (e.g., adults aged $\geq 18$ years, taking prescription medications, and Arabs). Data collection was started in March 2019 and ended in March 2021 due to the COVID-19 pandemic which resulted in a postponement of many scheduled appointments. The patients in the list were invited and interviewed by three pharmacists prior or after their scheduled appointments after explaining the purpose of this research and receiving their verbal consent to participate.

\subsection{Research Instrument Translation and Validation}

SEAMS is a 13-item self-reported medication adherence scale. Each item is scored on a 3-point Likert-scale where participants are asked to choose their level of confidence in taking medications correctly under different circumstances $(1=$ not confident, $2=$ somewhat confident, and 3 = very confident). It was designed for patients with low literacy. The total score ranges from 13 to 39 where low scores indicate a low level of confidence and high scores indicate a high level of confidence.

Prior to translation and validation, permission was obtained from the developers. The forward-backward translation method was used in which native Arabic speakers with high English proficiency levels translated SEAMS into Arabic. The 13-item Arabic translated version of SEAMS was checked for its face and content validity by all authors. Backward translation was performed by a healthcare professional whose native language is English but is proficient in Arabic. Thereafter, the preliminary version of the Arabic-SEAMS was pilot tested between 22 patients with chronic diseases to check its comprehensibility and clarity before being presented to them again after two weeks to examine its reliability using the test-retest method. The final version of 13-item Arabic SEAMS was then approved by all authors after making minor changes based on the responses of the pilot group (Appendix A).

Additionally, participants' sociodemographic characteristics, such as age, gender, educational level, and marital status, as well as medical characteristics (e.g., chronic diseases and prescription medication number) were collected. Furthermore, health literacy was assessed using the single item literacy screener (SILS), which consisted of one question inquiring about the need of the participant for help in understanding prescription drug leaflets or patient education materials. Those who choose "sometimes", "often", or "always" from the five possible answers (e.g., (5) always, (4) often, (3) sometimes, (2) rarely, and (1) never) are considered having limited or marginal health literacy. On the other hand, those who choose "rarely" or "never" are considered to have adequate health literacy $[18,19]$.

\subsection{Statistical Analysis}

The minimum sample size required for this study was estimated to be 192 subjects using GPower ${ }^{\circledR}$ software version 3.1 (Heinrich Heine University, Düsseldorf, Germany) for a medium effect size (e.g., Cohen's $d=0.3$ ), $\alpha=0.05, \beta=0.15$, a power of $85 \%$. Therefore, a $27.27 \%$ attrition rate out of the randomly created list of 264 patients who met the inclusion criteria would be acceptable. Frequencies, percentages, and mean \pm standard deviation (SD) were used to describe the participants' characteristics and the scores of the 13-item Arabic-SEAMS. Intraclass correlation-coefficient (ICC) was used to evaluate the test-retest reliability of the Arabic-SEAMS, and the Cronbach's alpha coefficient was used to examine its internal consistency [20-22]. Exploratory factor analysis was used in assessing the internal structure of the translated SEAMS. Items with a loading of 0.30 or greater were considered for inclusion in a separate factor [23]. Kaiser-Mayer-Olkin (KMO) measure of adequacy was also used, and value greater than 0.6 proves the adequacy of the sample [24]. Discriminant validity was ensured if the square root of the average variance extracted (AVE) is higher than correlation coefficient between the extracted factors [25]. Convergent validity 
was checked using the composite reliability with a cutoff point of $\geq 0.6$ [26]. Statistical analysis was conducted using SAS ${ }^{\circledR}$ version 9.4 (SAS ${ }^{\circledR}$ institute, Cary, NC, USA).

\subsection{Ethical Approval}

This research was approved by the institutional review board of King Saud University College of Medicine (Ref. No. 19/0271/IRB, E-19-3721, 10 March 2019). No personal identifiers, such as name or medical record numbers, were collected and all respondents gave their consent to participate. Only the authors of the study had access to the data, and the study adhered to the ethical principles of the Helsinki declaration [27].

\section{Results}

The number of patients who were recruited to this study was 202, resulting in a $76.52 \%$ response rate. Most of the patients were males (69.9\%), Saudi nationals (98\%), living in Riyadh (80.7\%), aged between 42 and 65 years $(56.9 \%)$, married $(75.2 \%)$, had a post-secondary diploma or higher $(50.9 \%)$, and had adequate health literacy $(79.2 \%)$. The most common chronic diseases among participants were diabetes $(96.53 \%)$, dyslipidemia $(48.01 \%)$, and hypertension (49.01), and $57.9 \%$ of the study population were taking six medications or more (Table 1 ).

Table 1. Study participants' sociodemographic characteristics $(n=202)$.

\begin{tabular}{cc}
\hline Gender & \\
\hline Male & $141(69.80)$ \\
\hline Female & $61(30.20)$ \\
\hline Age group (years) & $22(10.89)$ \\
\hline $18-25$ & $11(5.45)$ \\
\hline $26-33$ & $14(6.93)$ \\
\hline $34-41$ & $23(11.39)$ \\
\hline $42-49$ & $34(16.83)$ \\
\hline $50-57$ & $58(28.71)$ \\
\hline $58-65$ & $40(19.80)$ \\
\hline$>65$ & $30(14.85)$ \\
\hline Marital status & $152(75.25)$ \\
\hline Single & $20(9.90)$ \\
\hline Married & $15(7.43)$ \\
\hline Divorced/widowed & $76(37.62)$ \\
\hline Educational level & $12(5.94)$ \\
\hline No official education & $13(6.44)$ \\
\hline Elementary school diploma & $39(19.31)$ \\
\hline Middle school diploma & \\
\hline Associate degree & \\
\hline of Science or equivalent & \\
\hline Draduate degree (master of science or doctor of philosophy) \\
\hline
\end{tabular}


Table 1. Cont.

\begin{tabular}{cc}
\hline Gender & \\
\hline Chronic health conditions & $195(96.53)$ \\
\hline Diabetes & $99(49.01)$ \\
\hline Hypertension & $97(48.01)$ \\
\hline Dyslipidemia & $15(7.43)$ \\
\hline Asthma & $12(5.94)$ \\
\hline Cardiovascular disease & $32(15.84)$ \\
\hline Number of prescription medications & $35(17.33)$ \\
\hline $1-2$ & $18(8.91)$ \\
\hline $3-4$ & $117(57.92)$ \\
\hline $5-6$ & $160(79.21)$ \\
\hline$>6$ & $42(20.79)$ \\
\hline Health literacy &
\end{tabular}

Item analysis of the 13-item Arabic translated SEAMS scale is presented in Table 2. The intraclass correlation coefficient (ICC) of the translated scale was 0.975 indicating excellent reliability. The mean item scores ranged between 2.24 and 2.74, while the mean total score was 32.36 with a standard deviation of 5.31. Convergent validity was ensured by having a composite reliability of 0.95 , which is higher than the cutoff point of $\geq 0.6$, and the square root of the AVEs for the two extracted factors were 0.71 and 0.65 for factor- 1 and factor-2, respectively, which ensures discriminant validity since the AVEs for the two factors are higher than the correlation coefficient between the two factors (e.g., 0.59). Older age $(r=0.201, p=0.004)$, dyslipidemia $(r=0.165, p=0.018)$, and adequate health literacy $(\mathrm{r}=0.238, p=0.0006)$ were positively associated with higher SEAMS scores.

Table 2. Item analysis of the 13-item Arabic-SEAMS.

\begin{tabular}{|c|c|c|c|}
\hline Item & Mean \pm SD & $\begin{array}{l}\text { Item-Total } \\
\text { Correlation }\end{array}$ & $\begin{array}{l}\text { Cronbach's } \alpha \text { if } \\
\text { Item Deleted }\end{array}$ \\
\hline 1- When you take several different medicines each day? & $2.74 \pm 0.52$ & 0.56 & 0.878 \\
\hline 2- When you have a busy day planned? & $2.57 \pm 0.56$ & 0.62 & 0.875 \\
\hline 3- When you are away from home? & $2.51 \pm 0.64$ & 0.67 & 0.873 \\
\hline 4- When no one reminds you to take the medicine? & $2.57 \pm 0.64$ & 0.57 & 0.877 \\
\hline 5- When you take medicines more than once a day? & $2.63 \pm 0.58$ & 0.66 & 0.873 \\
\hline 6- When the schedule to take the medicine is not convenient? & $2.49 \pm 0.64$ & 0.57 & 0.878 \\
\hline 7- When your normal routine gets messed up? & $2.47 \pm 0.60$ & 0.68 & 0.872 \\
\hline $\begin{array}{l}\text { 8- When you get a refill of your old medicines and some of the pills } \\
\text { look different than usual? }\end{array}$ & $2.38 \pm 0.70$ & 0.49 & 0.881 \\
\hline 9- When you are not sure how to take the medicine? & $2.24 \pm 0.71$ & 0.49 & 0.882 \\
\hline $\begin{array}{l}\text { 10- When you are not sure what time of the day to take your } \\
\text { medicine? }\end{array}$ & $2.33 \pm 0.65$ & 0.55 & 0.879 \\
\hline 11- When a doctor changes your medicines? & $2.57 \pm 0.61$ & 0.50 & 0.881 \\
\hline 12- When they cause some side effects? & $2.19 \pm 0.66$ & 0.48 & 0.883 \\
\hline 13- When you are feeling sick (like having a cold or the flu)? & $2.60 \pm 0.59$ & 0.56 & 0.879 \\
\hline
\end{tabular}


The item-total correlation coefficient has shown moderate to strong correlation of all 13 items to the total scale, ranging from 0.48 to 0.82 . The Cronbach's alpha of the overall scale was 0.88 , indicating good internal consistency, and the deletion of any item on the scale did not result in improved internal consistency. Using the principal component analysis with varimax rotation, two factors were extracted from the Arabic 13-item SEAMS as shown in Table 3. Factor 1 which included items 1, 2, 3, 4, 5, 6, and 7 accounted for $57.73 \%$ of the variance, while factor 2 which included items $8,9,10,11,12$, and 13 accounted for $42.27 \%$ of the variance. The two factors have accounted for $100 \%$ of the total variance. The confirmatory factor analysis confirmed the goodness of fit of the two extracted factors (e.g., Bentler Comparative Fit Index $=0.98$, and RMSEA < 0.001).

Table 3. Factor Analysis of the 13-item Arabic-SEAMS (Varimax rotation method).

\begin{tabular}{ll}
\hline \multicolumn{1}{c}{ Item } & Factor-1 \\
\hline 1- When you take several different medicines each day? & $\mathbf{0 . 7 0 8}$ \\
\hline 2-When you have a busy day planned? & $\mathbf{0 . 8 1 5}$ \\
\hline 3- When you are away from home? & $\mathbf{0 . 7 5 0}$ \\
\hline 4- When no one reminds you to take the medicine? & $\mathbf{0 . 6 4 3}$ \\
\hline 5- When you take medicines more than once a day? & $\mathbf{0 . 7 8 0}$ \\
\hline 6- When the schedule to take the medicine is not convenient? & $\mathbf{0 . 6 2 1}$ \\
\hline 7- When your normal routine gets messed up? & $\mathbf{0 . 6 7 7}$ \\
\hline 8- When you get a refill of your old medicines and some of the pills look different than usual? & $\mathbf{0 . 5 3 2}$ \\
\hline 9- When you are not sure how to take the medicine? & $\mathbf{0 . 8 1 4}$ \\
\hline 10- When you are not sure what time of the day to take your medicine? & $\mathbf{0 . 7 9 8}$ \\
\hline 11- When a doctor changes your medicines? & $\mathbf{0 . 4 7 8}$ \\
\hline 12- When they cause some side effects? & $\mathbf{0 . 6 6 8}$ \\
\hline 13- When you are feeling sick (like having a cold or the flu)? & $\mathbf{0 . 5 3 7}$ \\
\hline
\end{tabular}

\section{Discussion}

The 13-item SEAMS is an effective and reliable self-report scale to measure self-efficacy for medication adherence that is useful in assessing poor or low self-efficacy for medication adherence among patients with chronic health conditions with limited health literacy [16]. It has been translated and validated into different languages, such as Portuguese [17], Taiwanese [28], Thai [29], and Chinese [30]. However, it does not exist in Arabic, which is the world's sixth most spoken language [31]. Sadly, Arabic speaking patients do not get their self-efficacy for medication adherence to prescribed medicines checked regularly due to the absence of valid and freely available scales [32]. In this study, the 13-item Arabic translated SEAMS demonstrated good validity and reliability. This was shown in the factor analysis that extracted two factors. The first factor included items 1, 2, 3, $4,5,6$, and 7, while the second factor included items $8,9,10,11,12$, and 13 . These factors were represented in the original paper as two clear dimensions, self-efficacy for taking medications under difficult circumstances (factor 1) and self-efficacy for continuing to take medications when circumstances surrounding medication-taking are uncertain (factor 2) [16]. Additionally, it had good internal consistency with a Cronbach's alpha of 0.88 [33], which is quite similar to the one reported for the original English scale (Cronbach's alpha $=0.89$ ) [16]. Moreover, the Arabic SEAMS reliability was further confirmed in the testretest with an ICC of 0.97. This shows that the Arabic SEAMS has comparable reliability, if not higher, to other medication adherence and self-efficacy for medication adherence assessment scales that have been validated into Arabic, but are not easily accessible or freely available, such as the MMAS-8 and MARS [32-34]. 
Health literacy was positively associated with higher SEAMS scores, which means that patients with adequate health literacy were more likely to adhere to their prescribed medicines than those with limited health literacy. This is consistent with the preponderance of evidence that shows a positive correlation between health literacy and medication adherence [35]. Interestingly, dyslipidemia was positively associated with higher SEAMS score. This finding may be related to the fact that most patients with dyslipidemia in the study were on statins, such as atorvastatin and simvastatin. The use of statins was positively associated with a higher medication adherence among a sample of Arabicspeaking patients with dyslipidemia in Jordan [36]. Another interesting finding was the positive association between older age and SEAMS score. Although many tend to think that adherence declines with age [37], other studies suggest that older adults (e.g., $\geq 65$ yrs.) are more likely to adhere to their prescribed treatment regimens in comparison to their younger counterparts [38].

Although this is the first study to the best of our knowledge that translated and validated the 13-item SEAMS into Arabic, some limitations should be acknowledged. First, the majority of patients in the study had adequate health literacy, contrary to the original study that evaluated the psychometric properties of the scale among low-literacy patients [16]. Therefore, the comprehensibility of the translated scale needs to be assessed further among patients with low-literacy levels. Moreover, health literacy was assessed using the single item literacy screener (SILS). Though SILS is a valid tool to assess health literacy, it is not as reliable as other scales [19], such as the 67-item Test of Functional Health Literacy (TOFHL), which was not used due to the time constraint associated with administering such a lengthy questionnaire [39]. Additionally, this was a single center study and the majority of patients were Saudi $(98 \%)$ which may limit the generalizability of the study findings. However, the Arabic language and terms used can be easily understood by any native Arabic speaker. Additionally, the Arabic-SEAMS was not cross-checked using other adherence assessment methods, such as pill counts and medication possession ratios [11].

\section{Conclusions}

The 13-item Arabic-translated SEAMS showed acceptable levels of validity and reliability, which makes it a valid option to assess self-efficacy for medication adherence among Arabic-speaking patients with different chronic health conditions and variable levels of health literacy. Furthermore, it should aid in improving patient care for native Arabicspeaking patients and minimize unnecessary costs and overall burden. Future studies should examine the psychometric properties of the Arabic-SEAMS among larger samples of patients with chronic health conditions, and particularly those with low-literacy levels. Additionally, the concurrent validity of the Arabic-SEAMS should be examined using other valid adherence measures, such as pill counts or medication possession ratios.

Author Contributions: Concept and design: G.A., H.A., N.A. and Y.A.; acquisition, analysis, and/or interpretation of data: Y.A., G.A., H.A., N.A., Y.A.A. and I.S.; drafting of the manuscript: G.A., Y.A., I.S., A.J., T.H.A., M.A.B. and I.S.; critical revision of the manuscript for important intellectual content: all authors; statistical analyses: Y.A. and I.S.; administrative, technical, and/or material support: Y.A., N.A., G.A., H.A., I.S., A.J., T.H.A., M.A.B. and Y.A.A. All authors have read and agreed to the published version of the manuscript.

Funding: The authors acknowledge the financial support received from the Researchers Supporting Project number (RSP-2021/16), King Saud University, Riyadh, Saudi Arabia.

Institutional Review Board Statement: The study protocol was approved by the institutional review board of the College of Medicine at King Saud University (E-19-3721, 10 March 2019), and all participants provided verbal informed consent. No patient identifiers will be used or kept by the researcher after conduction of the study.

Informed Consent Statement: Informed consent was obtained from all subjects involved in the study. 
Data Availability Statement: The data are available upon reasonable request from the corresponding. Author (Yazed AlRuthia).

Acknowledgments: The authors would like to thank Jessica Risser for the authorization of translating and validating the Self-Efficacy for Appropriate Medication Use Scale (SEAMS) into Arabic.

Conflicts of Interest: The authors declare no conflict of interest.

\section{Appendix A}

Table A1. Self-Efficacy for Appropriate Medication Use Scale (SEAMS).

\begin{tabular}{lcc}
\hline How Confident Are You That You Can Take Your Medicines Correctly? & $\begin{array}{c}\text { Not at All } \\
\text { Confident }\end{array}$ & $\begin{array}{c}\text { Somewhat } \\
\text { Confident }\end{array}$ \\
Confident
\end{tabular}

\section{References}

1. Tran, D.K.; Angelos, P. How Should Shared Decision Making Be Taught? AMA J. Ethics 2020, 22, 388-394. [PubMed]

2. Fiorillo, A.; Barlati, S.; Bellomo, A.; Corrivetti, G.; Nicolò, G.; Sampogna, G.; Stanga, V.; Veltro, F.; Maina, G.; Vita, A. The role of shared decision-making in improving adherence to pharmacological treat-ments in patients with schizophrenia: A clinical review. Ann. Gen. Psychiatry 2020, 19, 43. [CrossRef] [PubMed]

3. Chakrabarti, S. What's in a name? Compliance, adherence and concordance in chronic psychiatric disorders. World J. Psychiatry 2014, 4, 30-36. [CrossRef]

4. Kleinsinger, F. The Unmet Challenge of Medication Nonadherence. Perm. J. 2018, 22, 18-33. [CrossRef] [PubMed]

5. Cutler, R.L.; Fernandez-Llimos, F.; Frommer, M.; Benrimoj, C.; Garcia-Cardenas, V. Economic impact of medication non-adherence by disease groups: A systematic review. BMJ Open 2018, 8, e016982. [CrossRef] [PubMed]

6. Gast, A.; Mathes, T. Medication adherence influencing factors-An (updated) overview of systematic reviews. Syst. Rev. 2019, 8, 1-17. [CrossRef]

7. Brown, M.T.; Bussell, J.K. Medication adherence: Who cares? Mayo Clin. Proc. 2011, 86, 304-314. [CrossRef]

8. Hardy, G.E. The burden of chronic disease: The future is prevention. Introduction to Dr. James Marks' presentation, “The Burden of Chronic Disease and the Future of Public Health". Prev. Chronic Dis. 2004, 1, A04. [PubMed]

9. Abegaz, T.M.; Shehab, A.; Gebreyohannes, E.A.; Bhagavathula, A.S.; Elnour, A.A. Nonadherence to antihypertensive drugs: A systematic review and meta-analysis. Medicine 2017, 96, e5641. [CrossRef]

10. Raum, E.; Krämer, H.U.; Rüter, G.; Rothenbacher, D.; Rosemann, T.; Szecsenyi, J.; Brenner, H. Medication non-adherence and poor glycaemic control in patients with type 2 diabetes mellitus. Diabetes Res. Clin. Pract. 2012, 97, 377-384. [CrossRef]

11. Lam, W.Y.; Fresco, P. Medication Adherence Measures: An Overview. BioMed Res. Int. 2015, 2015, 1-12. [CrossRef]

12. Garfield, S.; Clifford, S.; Eliasson, L.; Barber, N.; Willson, A. Suitability of measures of self-reported medication adherence for routine clinical use: A systematic review. BMC Med. Res. Methodol. 2011, 11, 149. [CrossRef]

13. Alghurair, S.A.; Hughes, C.A.; Simpson, S.; Guirguis, L.M. A Systematic Review of Patient Self-Reported Barriers of Adherence to Antihypertensive Medications Using the World Health Organization Multidimensional Adherence Model. J. Clin. Hypertens. 2012, 14, 877-886. [CrossRef] 
14. Tan, X.; Patel, I.; Chang, J. Review of the four item Morisky Medication Adherence Scale (MMAS-4) and eight item Morisky Medication Adherence Scale (MMAS-8). Innov. Pharm. 2014, 5. [CrossRef]

15. Chan, A.H.Y.; Horne, R.; Hankins, M.; Chisari, C. The Medication Adherence Report Scale: A measurement tool for eliciting patients' reports of nonadherence. Br. J. Clin. Pharmacol. 2019, 86, 1281-1288. [CrossRef] [PubMed]

16. Risser, J.; Jacobson, T.; Kripalani, S. Development and Psychometric Evaluation of the Self-Efficacy for Appropriate Medication Use Scale (SEAMS) in Low-Literacy Patients with Chronic Disease. J. Nurs. Meas. 2007, 15, 203-219. [CrossRef]

17. Pedrosa, R.B.D.S.; Rodrigues, R.C.M. Adaptation and evaluation of the measurement properties of the Brazilian version of the Self-efficacy for Appropriate Medication Adherence ScaleRev. Rev. Lat. Am. Enferm. 2016, 24, e2692. [CrossRef] [PubMed]

18. Al-Jumaili, A.A.; Alrekabi, M.; Sorofman, B. Evaluation of instruments to assess health literacy in Arabic language among Iraqis. Res. Soc. Adm. Pharm. 2015, 11, 803-813. [CrossRef]

19. Morris, N.S.; MacLean, C.D.; Chew, L.D.; Littenberg, B. The Single Item Literacy Screener: Evaluation of a brief instrument to identify limited reading ability. BMC Fam. Pract. 2006, 7, 21. [CrossRef] [PubMed]

20. Perinetti, G. StaTips Part IV: Selection, interpretation and reporting of the intraclass correlation coefficient. South Eur. J. Orthod. Dentofac. Res. 2018, 5. [CrossRef]

21. Ursachi, G.; Horodnic, I.A.; Zait, A. How Reliable are Measurement Scales? External Factors with Indirect Influence on Reliability Estimators. Procedia Econ. Financ. 2015, 20, 679-686. [CrossRef]

22. Liljequist, D.; Elfving, B.; Roaldsen, K.S. Intraclass correlation-A discussion and demonstration of basic features. PLoS ONE 2019, 14, e0219854. [CrossRef] [PubMed]

23. Ledesma, R.D.; Valero-Mora, P. Determining the number of factors to retain in EFA: An easy-to-use computer program for carrying out parallel analysis. Pract. Assess. Res. Eval. 2007, 12, 2.

24. Williams, B.; Onsman, A.; Brown, T. Exploratory factor analysis: A five-step guide for novices. Australas. J. Paramed. 2010, 8. [CrossRef]

25. Ab Hamid, M.R.; Sami, W.; Sidek, M.M. Discriminant validity assessment: Use of Fornell \& Larcker criterion versus HTMT criterion. J. Phys. Conf. Ser. 2017, 890, 012163.

26. Fornell, C.; Larcker, D.F. Evaluating structural equation models with unobservable variables and measurement error. J. Mark. Res. 1981, 18, 39-50. [CrossRef]

27. Association, W.M. World Medical Association Declaration of Helsinki. Ethical principles for medical research involving human subjects. Bull. World Health Organ. 2001, 79, 373.

28. Chen, P.-T.; Wang, T.-J. Translation and Validation of the Taiwanese Version of the Self-Efficacy for Appropriate Medication Use Scale. Open J. Nurs. 2017, 7, 28-38. [CrossRef]

29. Polsook, R.; Aungsuroch, Y.; Thanasilp, S.; Duffy, J.R. Validity and Reliability of Thai Version of Questionnaire Measuring Self-efficacy for Appropriate Medication Use Scale among Thai with post-myocardial infarction. Songklanakarin J. Sci. Technol. 2014, 36, 411-417.

30. Dong, X.F.; Liu, Y.J.; Wang, A.X.; Lv, P.H. Psychometric properties of the Chinese version of the Self-Efficacy for Appropriate Med-ication Use Scale in patients with stroke. Patient Prefer Adherence 2016, 10, 321-327.

31. Ammon, U. World languages: Trends and futures. Handb. Lang. Glob. 2010, 64, 101-122.

32. Ashur, S.; Shamsuddin, K.; Shah, S.; Bosseri, S.; Morisky, D. Reliability and known-group validity of the Arabic version of the 8-item Morisky Medication Adherence Scale among type 2 diabetes mellitus patients. East. Mediterr. Health J. 2015, 21, 722-728. [CrossRef]

33. Tavakol, M.; Dennick, R. Making sense of Cronbach's alpha. Int. J. Med. Educ. 2011, 2, 53-55. [CrossRef]

34. AlSous, M.; Alhalaiqa, F.; Abu Farha, R.; Jalil, M.A.; McElnay, J.; Horne, R. Reliability and validity of Arabic translation of Medication Adherence Report Scale (MARS) and Beliefs about Medication Questionnaire (BMQ)-specific for use in children and their parents. PLoS ONE 2017, 12, e0171863. [CrossRef]

35. Lee, Y.-M.; Yu, H.Y.; You, M.-A.; Son, Y.-J. Impact of health literacy on medication adherence in older people with chronic diseases. Collegian 2015, 24, 11-18. [CrossRef]

36. Alefishat, E.; Jarab, A.; Al-Qerem, W.; Abu-Zaytoun, L. Factors Associated with Medication Non-Adherence in Patients with Dyslipidemia. Healthcare 2021, 9, 813. [CrossRef] [PubMed]

37. Smaje, A.; Weston-Clark, M.; Raj, R.; Orlu, M.; Davis, D.; Rawle, M. Factors associated with medication adherence in older patients: A systematic review. Aging Med. 2018, 1, 254-266. [CrossRef] [PubMed]

38. Leven, E.A.; Annunziato, R.; Helcer, J.; Lieber, S.; Knight, C.S.; Wlodarkiewicz, C.; Soriano, R.P.; Florman, S.S.; Schiano, T.D.; Shemesh, E. Medication adherence and rejection rates in older vs younger adult liver transplant recipients. Clin. Transp. 2017, 31, e12981. [CrossRef] [PubMed]

39. Tian, C.Y.; Xu, R.H.; Mo, P.K.-H.; Dong, D.; Wong, E.L.-Y. Generic Health Literacy Measurements for Adults: A Scoping Review. Int. J. Environ. Res. Public Health 2020, 17, 7768. [CrossRef] [PubMed] 